\title{
Perancangan Sistem Otomatisasi Penyalaan Lampu, Kipas Angin, dan Proyektor Dalam Ruang Kelas
}

\author{
Reza Satria Rinaldi ${ }^{*}$, Yosri Riadi Lase ${ }^{1}$, Muhammad K. Amri Rosa ${ }^{1}$ \\ ${ }^{1}$ Program Studi Teknik Elektro Fakultas Teknik Universitas Bengkulu, *reza_s_r@unib.ac.id
}

\begin{abstract}
AbSTRAK
In general, the control of using electronic equipment in the classroom manually. Sometimes lecturers or students forget to turn off electronic equipment after the class so that there is a waste of electrical energy use. Application of automation of using electronic equipment is one solution to overcome these problems so that electrical energy becomes more efficient. This study designed a prototype of an automation system for electrical equipment in the classroom, namely lights, fans, and projectors. This system was also to turn off the electricity when nobody was in the class. The automation system controls the use of electrical energy in devices in the classroom through on-off control of the electrical network components connected to each device. In this design, the PIR sensor can detect the presence of people up to a distance of 7 meters. The Arduino Uno controller activates the lights in the class when the LDR Sensor detects a light intensity of less than 200 Lux. Then, the fan is active when the LM35 sensor detects the temperature in the class above $280 \mathrm{C}$. The FC-04 sensor detects the sound of clapping for control of projector ignition.
\end{abstract}

Kata kunci: Otomatisasi, PIR, LDR, LM35, Sensor.

\section{Pendahuluan}

Energi listrik menjadi salah satu kebutuhan utama dalam pelaksanaan kegiatan di kampus. Sejumlah peralatan elektronik yang membutuhkan energi listrik dipergunakan dalam proses pembelajaran di kampus, khususnya di ruang kelas. Penggunaan peralatan elektronik tersebut sangat membantu kelancaran proses pembelajaran. Pada umumnya pemakaian energi listrik pada peralatan elektronik dalam ruang kelas dikendalikan secara manual. Terkadang setelah proses pembelajaran dosen atau mahasiswa lupa mematikan peralatan elektronik yang digunakan di kelas. Dengan demikian tidak dapat dihindarkan akan terjadinya pemborosan penggunaan energi listrik untuk peralatan tersebut. Salah satu solusi yang dapat dilakukan untuk mengatasi hal tersebut adalah dengan otomatisasi penggunaan energi listrik pada peralatan elektronik dalam ruang kelas.
Dengan penerapan otomatisasi penggunaan energi listrik pada peralatan elektronik, maka penggunaan energi listrik menjadi lebih efisien. Sistem kendali dengan memanfaatkan sejumlah sensor dapat digunakan untuk menciptakan otomatisasi tersebut di atas.

Saklar otomatis digunakan untuk mengoperasikan beban lampu penerangan suatu ruangan. Saklar otomatis dirancang menggunakan sensor PIR (Passive Infra Red) dan sensor LDR (Light Dependent Resistor). Kehadiran orang dalam ruangan dideteksi oleh sensor PIR, sedangakan sensor LDR digunakan untuk mendeteksi kuatnya intensitas cahaya dalam ruangan. Penelitian ini hanya berupa simulasi dan uji coba rangkaian elektronik sistem saklar otomatis lampu. Sensor LDR digunakan sebagai masukan kendali nyala lampu saat ada orang dalam ruangan ketika intensitas cahaya dalam ruangan kurang. Sensor PIR berfungsi sebagai masukan kendali lampu berdasarkan keberadaan orang dalam ruangan. Ketika pengguna meninggalkan ruangan, maka dalam durasi yang telah ditentukan lampu penerangan ruangan tersebut akan dimatikan secara otomatis berdasarkan masukan sensor PIR. Agar lebih sederhana dari rangkaian sejenis sebelumnya, digunakan kontroler Arduino Uno ATmega 328 [1].

Sensor PIR, LM35, dan LDR digunakan dalam sebuah sistem pengendali peralatan elektronik dalam rumah secara otomatis. Sistem pengendali dalam penelitian ini berupa prototipe rumah dengan perangkat elektronik sistem kendali. Mikrokontroler ATMega16 digunakan sebagai pusat pengolahan data masukan dan keluaran sistem. Sensor LDR dapat membedakan gelap dan terang, sensor suhu LM35 dapat mendeteksi suhu dalam ruangan dengan toleransi $2^{\circ} \mathrm{C}$, dan sensor PIR dapat mendeteksi pergerakan manusia hingga jarak 5 meter. Saat ada manusia dalam rumah dan keluaran sensor LDR lebih besar dari $250 \mathrm{bit} / \mathrm{second} \mathrm{maka} \mathrm{lampu} \mathrm{mati,} \mathrm{sedangkan}$ saat keluaran sensor LDR hingga 250 bit/second maka lampu hidup. Pendingin ruangan menyala ketika ada manusia dalam rumah dan sensor LM35 mendeteksi suhu mulai dari $18^{\circ} \mathrm{C}$. Sistem dan peralatan elektronik tertentu dalam rumah akan mati bila sensor PIR tidak 
mendeteksi adanya manusia dalam rumah [2].

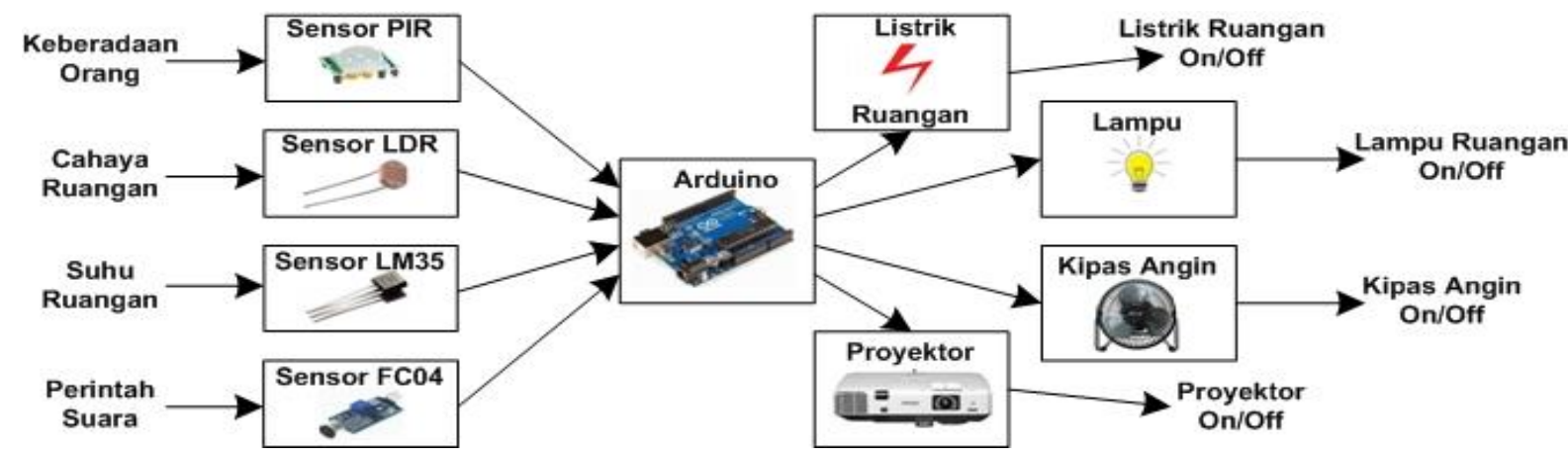

Gambar 1. Blok Diagram Sistem

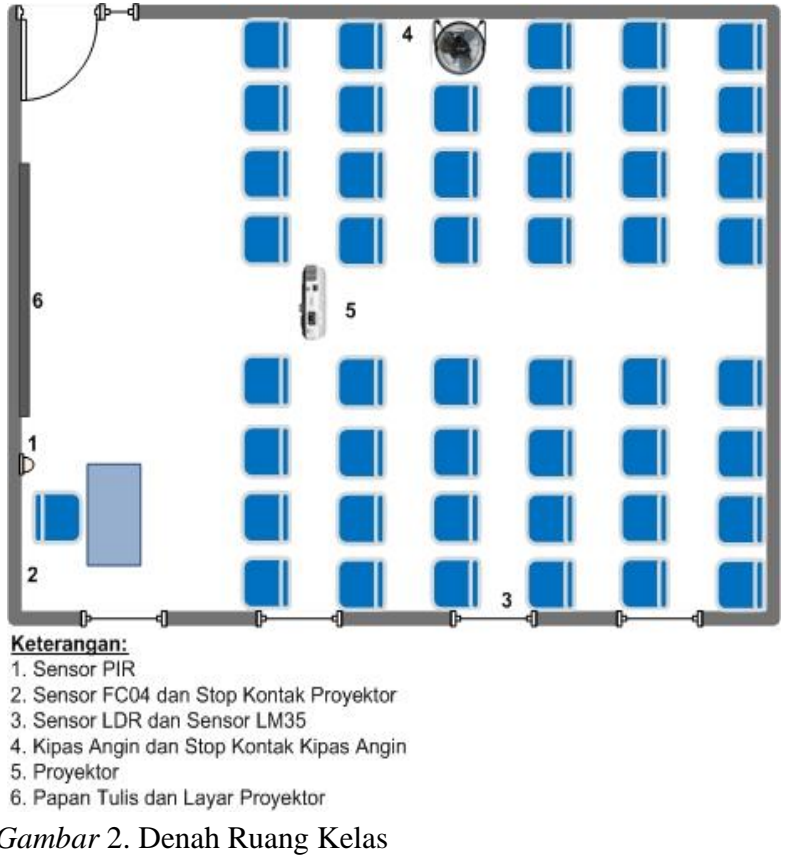

Berdasarkan latar belakang di atas, maka dalam penelitian ini dilakukan perancangan sebuah prototipe sistem otomatisasi penyalaan peralatan listrik dalam sebuah ruang kelas Otomatisasi penyalaan ini diterapkan pada peralatan listrik berupa lampu, kipas angin, proyektor dan listrik ruang kelas secara keseluruhan. Sistem otomatisasi ini dirancang berupa prototipe yang dibuat agar listrik di ruang kelas non-aktif (off) saat tidak ada orang yang berada dalam ruang kelas. Dalam perancangan ini digunakan 4 buah sensor sebagai pendeteksi besaran masukan, yaitu sensor PIR, sensor LDR, sensor LM35 dan sensor FC-04.

\section{MATERI DAN Metode}

Prototipe sistem otomatisasi penyalaan listrik, lampu, kipas angin, dan proyektor pada ruang kelas ini dirancang dengan metode Research and Development (R\&D). Diagram blok pada Gambar 1 menggambarkan rancangan hubungan antar komponen pada prototipe sistem. Peralatan listrik yang dikendalikan penyalaannya dalam sistem ini merupakan peralatan listrik yang terdapat dalam ruang kelas di Gedung Kuliah Bersama (GKB) V Universitas Bengkulu, yang digunakan sebagai ruang kuliah oleh mahasiswa Program Studi Teknik Elektro Fakultas Teknik Universitas Bengkulu. Denah ruang kelas beserta posisi penempatan komponen sistem otomatisasi ini dapat dilihat pada Gambar 2.

Sistem otomatisasi penyalaan perlatan listrik ini berupa sebuah sistem kendali lintasan terbuka (open loop) dengan 4 masukan dan 4 keluaran. Secara garis besar, sistem otomatisasi yang dirancang ini terdiri atas 3 bagian utama, yaitu:

1. bagian masukan, yang terdiri atas 4 parameter masukan yang masing-masing dideteksi oleh sensor agar bisa diproses oleh kontroller;

2. bagian kendali, menggunakan Arduino yang melakukan proses kendali sistem; dan

3. bagian keluaran, yang merupakan 4 perangkat yang diotomatisasi penyalaannya oleh sinyal kendali dari Arduino.

\section{A. Bagian Masukan}

Pada bagian masukan sistem, terdapat 4 parameter yang akan dideteksi oleh sensor, yaitu:

1. keberadaan orang dalam ruang kelas;

2. besar intensitas cahaya dalam ruang kelas;

3. suhu dalam ruang kelas; dan

4. perintah suara untuk mengaktifkan dan menonaktifkan proyektor dalam ruang kelas.

Sensor diperlukan untuk memperoleh sinyal keluaran pada sistem pemantauan; prediksi, deteksi, dan diagnosis kesalahan; memberikan peringatan dan nasihat; kontrol umpan balik; kendali pengawasan; mengukur sinyal input untuk pemodelan eksperimental; kendali umpan maju; dan untuk berbagai tujuan lainnya [3]. Keempat masukan di atas akan dideteksi oleh 4 sensor, yaitu:

1. sensor PIR (Passive Infra Red), yaitu untuk mendeteksi keberadaan orang dalam ruang kelas; 
2. sensor LDR (Light Dependent Resistor) untuk mendeteksi besar intensitas cahaya dalam ruang kelas;

3. sensor LM35 untuk mendeteksi suhu dalam ruang kelas; dan

4. sensor FC-04 untuk mendeteksi perintah suara mengaktifan/menon-aktifan proyektor.

Sensor PIR merupakan sensor yang digunakan untuk mendeteksi keberadaan manusia. Radiasi panas (infra mereah) tubuh manusia dideteksi oleh sensor PIR dan mengubahnya menjadi tegangan. Berdasarkan hasil pengujian, sensor PIR sensitifitas yang baik karena hanya mendeteksi suhu tubuh manusia. Apabila ada benda hidup lain seperti hewan yang bergerak, sensor tidak mendeteksi. Sensor dapat mendeteksi keberadaan manusia hingga jarak 5 meter. Dengan demikian, sensor PIR sangat efektif digunakan sebagai pendeteksi keberadaan manuasia [4].

Dalam penelitian ini digunakan sensor PIR HCSR501 untuk mendeteksi keberadaan orang dalam ruang kelas. Sensor PIR ditempatkan sedemikian rupa seperti pada Gambar 2 agar dapat optimal dalam mendeteksi keberadaan orang dalam ruang kelas. Keberadaan orang dalam kelas akan menjadi penentu bagi sistem kendali untuk mengaktifkan atau menon-aktifkan listrik dalam ruang kelas. Bila tidak ada orang dalam kelas, maka listrik dalam kelas non-aktif sehingga semua peralatan listrik di dalam tidak dapat diaktifkan. Demikian juga setelah ruang kelas kelas dipergunakan, setelah tidak ada lagi orang dalam ruang kelas yang dideteksi oleh sensor PIR, maka listrik dalam kelas non-aktif sehingga semua peralatan listrik di dalam kelas kembali non-aktif.

Sensor LDR merupakan resistor yang peka terhadap cahaya. Nilai resistansinya dapat mengalami perubahan seiring dengan perubahan intensitas cahaya yang diterimanya. Nilai resistansi LDR pada tempat yang gelap biasanya mencapai hingga $10 \mathrm{M} \Omega$, sedangkan ditempat terang bisa turun mencapai $150 \Omega$ [5].

Sensor LDR dalam rancangan ini ditempatkan di atas jendela ruang kelas yang menerima cahaya dari luar gedung. LDR digunakan untuk mengukur intensitas cahaya dalam ruang kelas. Dalam rancangan ini diatur bila intensitas cahaya kurang dari 200 Lux, maka sistem kendali akan menyalakan lampu dalam ruang kelas. Proses ini dikendalikan dengan mengaktifkan atau menon-aktifkan aliran listrik ke lampu.

Sebuah sistem kipas otomatis yang secara otomatis mengubah tingkat kecepatan sesuai dengan perubahan suhu telah dibuat dengan menggunakan sensor LM35. Sensor LM35 mengendalikan kipas melalui Arduino Uno dengan mengukur suhu ruangan secara terus menerus.
Sensor LM35 menghasilkan tegangan $10 \mathrm{mV}$ untuk kenaikan suhu $1^{\circ} \mathrm{C}[6]$.

Kipas angin dalam ruang kelas pada penelitian ini akan aktif bila sensor LM35 mendeteksi suhu dalam ruang kelas di atas $28^{\circ} \mathrm{C}$. Pengaktifan kipas angin dalam rancangan ini dilakukan melalui pengendalian aliran listrik pada stop kontak yang terhubung ke kipas angin. Sedangkan untuk variasi kecepatan putaran kipas angin tetap dikendalikan secara manual.

Sensor FC-04 merupakan sebuah modul yang terdiri dari mikrofon kapasistif dan rangkaian amplifier. Sensor FC-04 digunakan untuk mengukur kebisingan atau suara di sekitarnya. Akurasi sensor ini dapat di atur menggunakan resistor variabel pada modul. Keluaran sensor ini berupa sinyal analog [7]. Sebuah sensor suara FC-04 digunakan untuk mendeteksi suara siulan. Intensitas suara yang terdeteksi sensor FC-04 dari 91,1 dBA pada putaran awal resistor variabel dan 95,4 dBA pada putaran akhir resistor variabel. Jadi, sensor FC-04 tidak dapat mendeteksi suara kurang dari 91,1 dBA dan suara lebih dari 95,4 dBA [8].

Dalam rancangan ini, sensor FC-04 digunakan sebagai parameter masukan untuk pengendalian penyalaan proyektor. Suara yang dideteksi berupa tepukan tangan. Sensor FC-04 ditempatkan di belakang kursi dosen dalam ruang kelas seperti pada Gambar 2, sehingga hanya suara tepukan tangan dari area kursi dosen saja yang akan dideteksi oleh sensor FC-04. Proses ini dikendalikan dengan mengaktifkan atau menon-aktifkan stop kontak yang terhubung ke proyektor.

\section{B. Bagian Kendali}

Sinyal keluaran keempat sensor merupakan sinyal masukan Arduino. Arduino dikenal sebagai proyek perangkat keras berbasis "open source" yang memudahkan pengguna untuk membuat prototipe sistem elektronik, Arduino uno telah dilengkapi dengan sejumlah pin digital dan analog yang memungkinkan digunakan untuk membaca sensor seperti sensor suhu dan kelembaban udara ataupun mengontrol aktuator [9].

Arduino sebagai pusat kendali sistem bertugas mengolah sinyal masukan dari sensor menjadi sinyal kendali. Sinyal kendali sebagai keluaran Arduino akan mengendalikan penggunaan energi listrik dalam ruang kelas, penggunaan energi listrik oleh lampu, kipas angin, dan proyektor dalam ruang kelas. Adapun skenario kerja otomatisasi yang akan dicapai adalah sebagai berikut.

1. Sistem mengaktifkan listrik dalam ruang kelas bila sensor PIR mendeteksi keberadaan orang dalam ruang kelas, dan sebaliknya ketika tidak ada orang dalam ruang kelas, maka sistem akan menonaktifkan listrik dalam ruang kelas.

2. Lampu dalam ruang kelas akan menyala bila sensor LDR mendeteksi intensitas cahaya kurang dari 
200 Lux. Jika intensitas cahaya lebih besar dari 200 Lux, maka lampu akan padam.

3. Kipas angin dalam ruang kelas hanya akan aktif ketika suhu dalam ruang kelas di atas $28^{\circ} \mathrm{C}$.

4. Proyektor dalam ruang kelas hanya akan aktif setelah ada perintah untuk megaktifkan proyektor melalui suara tepukan tangan.

Dengan kendali penyalaan kipas angin dan proyektor melalui stop kontak yang terhubung pada masing-masing peralatan, maka peralatan yang ada saat ini dapat digunakan dalam sistem. Melalui kendali menyalaan ini tidak terdapat modifikasi pada peralatan-peralatan tersebut.

\section{Bagian Keluaran}

Sinyal keluaran Arduino merupakan sinyal kendali untuk bagian keluaran sistem otomatisasi. Bagian keluaran sistem ini terdiri atas 4 perangkat dalam ruang kelas, yaitu:

1. jaringan listrik;

2. lampu;

3. kipas angin; dan

4. proyektor.

Keempat perangkat pada bagian keluaran di atas dikendalikan menggunakan kendali on-off yang diproses oleh Arduino. Sistem otomatisasi akan mengendalikan penggunaan energi listrik perangkat dalam ruang kelas melalui kendali on-off terhadap komponen jaringan listrik yang terhubung dengan masing-masing perangkat. Dengan demikian, meskipun terjadi penggantian perangkat lampu, kipas angin, maupun proyektor dalam ruang kelas, sistem otomatisasi ini tetap akan berfungsi. Rancangan sistem ini dapat diaplikasikan cukup dengan memodifikasi jaringan listrik setiap ruang kelas saja.

TABEL 1

Hasil Pengujian Kendali

JARINGAN LISTRIK RUANG KELAS

\begin{tabular}{ccc}
\hline $\begin{array}{c}\text { Jarak } \\
\text { Orang-PIR } \\
\text { (meter) }\end{array}$ & $\begin{array}{c}\text { Keberadaan } \\
\text { orang }\end{array}$ & $\begin{array}{c}\text { Jaringan Listrik } \\
\text { Ruang Kelas }\end{array}$ \\
\hline 0.2 & terdeteksi & Aktif \\
0.3 & terdeteksi & Aktif \\
0.6 & terdeteksi & Aktif \\
1 & terdeteksi & Aktif \\
1.5 & terdeteksi & Aktif \\
2 & terdeteksi & Aktif \\
3 & terdeteksi & Aktif \\
4 & terdeteksi & Aktif \\
5 & terdeteksi & Aktif \\
6 & terdeteksi & Aktif
\end{tabular}

\begin{tabular}{ccc}
7 & terdeteksi & Aktif \\
8 & tidak terdeteksi & Non Aktif \\
8,5 & tidak terdeteksi & Non Aktif \\
9 & tidak terdeteksi & Non Aktif \\
\hline \multicolumn{3}{r}{ 3. HASIL DAN PEMBAHASAN }
\end{tabular}

\section{A. Kendali Jaringan Listrik Ruang Kelas}

Kendali jaringan listrik dalam ruang kelas diuji melalui pengujian sensor PIR. Pengujian dilakukan untuk mengetahui jarak maksimal jangkauan sensor PIR mendeteksi keberadaan orang. Berdasarkan jangkauan pendeteksian keberadaan orang tersebut, akan dilihat hasil kendalinya untuk mengaktifkan/menon-aktifkan jaringan listrik dalam ruang kelas. Terdapat 14 variasi jarak pada pengujian ini, yaitu mulai dari 0,2 meter hingga beberapa data jarak ketika sensor PIR tidak lagi dapat mendeteksi keberadaan orang. Dalam pengujian ini, ditambahkan led untuk mempermudah dalam melihat respon sensor PIR. Jika led menyala, berarti ada orang dalam ruang kelas dan jaringan listrik dalam ruang kelas aktif. Sebaliknya, jika led tidak menyala, berarti tidak ada orang dalam ruang kelas sehingga jaringan listrik dalam ruang kelas dalam kondisi non-aktif. Hasil pengujian pada sensor PIR dapat dilihat pada Tabel 1 .

Berdasarkan hasil pengujian pada Tabel 1, dapat dilihat bahwa sensor PIR dapat mendeteksi keberadaan orang hingga jarak 7 meter. Hal ini sesuai dengan lembar data (data sheet) sensor PIR HC-SR501, yaitu mempunyai rentang pendeteksiam kurang dari $120^{\circ}$ dalam jarak 7 meter. Dengan keberadaan orang dalam ruang kelas, maka sensor PIR akan mengaktifkan jaringan listrik dalam ruang kelas melalui proses kendali oleh Arduino Uno.

\section{B. Kendali Lampu Ruang Kelas}

Pengujian pada sensor LDR dilakukan untuk mengetahui apakah kendali lampu dalam ruang kelas bekerja. Dalam pengujian ini dilakukan variasi intensitas cahaya dalam ruang kelas. Pengujian dilakukan dengan 11 variasi intensitas cahaya dari 0 Lux sampai 300 Lux.

TABEL 2

Hasil Pengujian Kendali Lampu Ruang Kelas

\begin{tabular}{ccc}
\hline $\begin{array}{c}\text { Intensitas } \\
\text { Cahaya (Lux) }\end{array}$ & $\begin{array}{c}\text { Tegangan LDR } \\
\text { (Volt) }\end{array}$ & $\begin{array}{c}\text { Lampu Ruang } \\
\text { Kelas }\end{array}$ \\
\hline 0 & 0.06 & Aktif \\
50 & 0.11 & Aktif \\
100 & 0.13 & Aktif \\
150 & 0.16 & Aktif \\
180 & 0.17 & Aktif \\
190 & 0.18 & Aktif \\
200 & 0.19 & Non Aktif
\end{tabular}




\begin{tabular}{lll}
210 & 0.2 & Non Aktif \\
220 & 0.21 & Non Aktif \\
250 & 0.22 & Non Aktif \\
300 & 0.23 & Non Aktif \\
\hline
\end{tabular}

TABEL 3

Hasil Pengujian Kendali Kipas Angin Ruang Kelas

\begin{tabular}{cccc}
\hline $\begin{array}{c}\text { Suhu } \\
\text { Pembacaan } \\
\text { Termometer } \\
\left({ }^{\circ} \mathrm{C}\right)\end{array}$ & $\begin{array}{c}\text { Suhu } \\
\text { Pembacaan } \\
\text { Sensor }\left({ }^{\circ} \mathrm{C}\right)\end{array}$ & $\begin{array}{c}\text { Tegangan } \\
\text { LM35 } \\
(\text { volt })\end{array}$ & $\begin{array}{c}\text { Kipas Angin } \\
\text { Ruang Kelas }\end{array}$ \\
\hline 25 & 24.9 & 0.035 & Non Aktif \\
27 & 26.37 & 0.042 & Non Aktif \\
28 & 27.8 & 0.053 & Non Aktif \\
29 & 29.13 & 0.061 & Aktif \\
30 & 29.46 & 0.073 & Aktif \\
31 & 31.23 & 0.084 & Aktif \\
32 & 31.84 & 0.097 & Aktif \\
\hline
\end{tabular}

Variasi ini dilakukan dengan mengatur jarak sumber cahaya pengujian terhadap sensor LDR. Pada setiap variasi dilakukan pengukuran nilai tegangan pada LDR dan kondisi lampu dalam ruang kelas. Tabel 2 memperlihatkan hasil pengujian tersebut.

Pada Tabel 2 dapat dilihat bahwa semakin tinggi intensitas cahaya, maka tegangan yang terukur pada LDR akan semakin tinggi. Hal ini sesuai dengan karakteristik LDR yang nilai resistansinya akan semakin turun bila intensitas cahaya yang diterimanya semakin besar. Lampu dalam ruang kelas akan menyala/aktif saat intensitas cahaya kurang dari 200 Lux. Hal ini menunjukkan bahwa LDR dan Arduino bekerja dengan baik dalam mengendalikan penggunaan energi listrik oleh lampu dalam ruang kelas.

\section{Kendali Kipas Angin Ruang Kelas}

Penggunaan energi listrik oleh kipas angin dalam ruang kelas dikendalikan oleh Arduino berdasarkan sinyal hasil deteksi suhu oleh sensor LM35. Dalam perancangan ini digunakan sensor LM35DZ. Pengujian dilakukan dengan beberapa variasi suhu ruangan. Untuk membuat suhu ruangan menjadi lebih panas digunakan kompor listrik yang diatur jaraknya sedemikian rupa dari sensor. Data yang diambil adalah data suhu pengukuran langsung menggunakan thermometer, data suhu keluaran sensor yang ditampilkan pada serial monitor, data tegangan sensor, dan kondisi kipas angin. Data ini disajikan pada Tabel 3.

Pada Tabel 3 dapat dilihat bahwa terdapat selisih hasil pembacaan suhu ruangan oleh termometer dan sensor. Selisih pembacaan suhu tersebut tidak begitu besar dan masih dalam batas toleransi yang bisa diterima, yaitu dibawah 5\%. Selisih pembacaan ini tidak signifikan pengaruhnya untuk perancangan sistem otomatisasi ini. Tegangan pada sensor LM35 naik seiring dengan kenaikan suhu. Setiap kenaikan suhu $1^{\circ} \mathrm{C}$ tegangan sensor LM35 rata-rata naik sebesar $10 \mathrm{mV}$.

TABEL 4

Hasil Pengujian Kendali Proyektor Ruang Kelas

\begin{tabular}{ccc}
\hline \multirow{2}{*}{$\begin{array}{c}\text { Pengambilan } \\
\text { Data ke- }\end{array}$} & \multicolumn{2}{c}{ Waktu Respon (detik) } \\
\cline { 2 - 3 } & $\begin{array}{c}\text { Mengaktifkan } \\
\text { Proyektor }\end{array}$ & $\begin{array}{c}\text { Menon-aktifkan } \\
\text { Proyektor }\end{array}$ \\
\hline $\mathbf{1}$ & 1 & 1 \\
$\mathbf{2}$ & 1 & 2 \\
$\mathbf{3}$ & 2 & 1 \\
$\mathbf{5}$ & 1 & 1 \\
$\mathbf{6}$ & 1 & 2 \\
$\mathbf{7}$ & 1 & 1 \\
$\mathbf{8}$ & 1 & 3 \\
$\mathbf{9}$ & 1 & 1 \\
$\mathbf{1 0}$ & 3 & 1 \\
\hline
\end{tabular}

\section{Kendali Proyektor Ruang Kelas}

Kendali penggunaan energi listrik dalam ruang kelas diuji dengan melakukan pengujian pada sensor suara FC-04. Pengujian dilakukan dengan menghitung waktu respon sensor FC-04 ketika diberi sumber suara berupa tepuk tangan. Sensitivitas sensor FC-04 diset pada nilai yang paling tinggi dan kemudian diambil sebanyak 10 data atau 10 kali pengulangan pengambilan data untuk setiap perlakuan. Perlakuan dalam pengambilan data ini ada 2, yaitu untuk menyalakan/mengaktifkan proyektor dan untuk mematikan/menon-aktifkan proyektor. Data yang dihasilkan dalam pengujian ini dapat dilihat pada Tabel 4.

Berdasarkan hasil yang diperoleh pada Tabel 4, waktu rata-rata yang dibutuhkan sensor untuk mengaktifkan proyektor adalah 1,3 detik dan waktu rata-rata yang dibutuhkan untuk menon-aktifkan proyektor adalah 1,4 detik. Sensor FC-04 memiliki 2 opsi, yaitu digital output dan analog output. Pada perancangan sistem otomatisasi ini digunakan kaki digital pada sensor FC-04 sehingga nilai yang ditampilkan pada serial monitor adalah 1 dan 0 atau High dan Low.

\section{E. Pengujian Keseluruhan Sistem}

Setelah dilakukan pengujian masing-masing proses kendali pada setiap perangkat pada bagian masukan, maka selanjutnya dilakukan pengujian sistem secara keseluruhan. Pengujian ini dilakukan secara dari 
pengujian ke-1 hingga pengujian ke-12 dengan hasil pengujian seperti pada Tabel 5 .

Berdasarkan hasil pengujian, pada Tabel 5 dapat dilihat bahwa secara keseluruhan sistem bekerja sesuai yang dirancang. Masing-masing sensor bekerja dengan baik. Jika dalam ruang kelas ada orang, maka sistem otomatisasi penyalaan peralatan listrik ruang bekerja.

TABEL 5

Hasil Pengujian KeSEluRUhan Sistem OtOMATISASI

\begin{tabular}{|c|c|c|c|c|c|c|c|c|}
\hline \multirow{2}{*}{$\begin{array}{c}\text { Pengujian } \\
\text { ke- }\end{array}$} & \multirow{2}{*}{$\begin{array}{c}\text { Hasil Deteksi } \\
\text { Sensor PIR }\end{array}$} & \multirow{2}{*}{$\begin{array}{c}\text { Hasil Deteksi } \\
\text { Sensor LDR } \\
\text { (Lux) }\end{array}$} & \multirow{2}{*}{$\begin{array}{c}\text { Hasil Deteksi } \\
\text { Sensor LM35 } \\
\left({ }^{\circ} \mathrm{C}\right)\end{array}$} & \multirow{2}{*}{$\begin{array}{l}\text { Hasil Deteksi } \\
\text { Sensor FC-04 }\end{array}$} & \multicolumn{4}{|c|}{ Status Perangkat Dalam Ruang Kelas } \\
\hline & & & & & $\begin{array}{c}\text { Listrik Ruang } \\
\text { Kelas }\end{array}$ & Lampu & Kipas Angin & Proyektor \\
\hline 1 & Ada orang & $<200$ & $<28$ & $\begin{array}{c}\text { Tidak ada } \\
\text { tepukan tangan }\end{array}$ & Aktif & Aktif & Non Aktif & Non Aktif \\
\hline 2 & Ada orang & $<200$ & $<28$ & $\begin{array}{l}\text { Ada tepukan } \\
\text { tangan }\end{array}$ & Aktif & Aktif & Non Aktif & Aktif \\
\hline 3 & Ada orang & $<200$ & $>28$ & $\begin{array}{c}\text { Tidak ada } \\
\text { tepukan tangan }\end{array}$ & Aktif & Aktif & Aktif & Aktif \\
\hline 4 & Ada orang & $<200$ & $>28$ & $\begin{array}{l}\text { Ada tepukan } \\
\text { tangan }\end{array}$ & Aktif & Aktif & Aktif & Non Aktif \\
\hline 5 & Ada orang & $>200$ & $>28$ & $\begin{array}{c}\text { Ada tepukan } \\
\text { tangan }\end{array}$ & Aktif & Non Aktif & Aktif & Aktif \\
\hline 6 & Ada orang & $>200$ & $>28$ & $\begin{array}{c}\text { Tidak ada } \\
\text { tepukan tangan }\end{array}$ & Aktif & Non Aktif & Aktif & Aktif \\
\hline 7 & Ada orang & $>200$ & $>28$ & $\begin{array}{l}\text { Ada tepukan } \\
\text { tangan }\end{array}$ & Aktif & Non Aktif & Aktif & Non Aktif \\
\hline 8 & Ada orang & $>200$ & $<28$ & $\begin{array}{c}\text { Tidak ada } \\
\text { tepukan tangan }\end{array}$ & Aktif & Non Aktif & Non Aktif & Non Aktif \\
\hline 9 & Ada orang & $>200$ & $<28$ & $\begin{array}{l}\text { Ada tepukan } \\
\text { tangan }\end{array}$ & Aktif & Non Aktif & Non Aktif & Aktif \\
\hline 10 & $\begin{array}{l}\text { Tidak ada } \\
\text { orang }\end{array}$ & $>200$ & $<28$ & $\begin{array}{c}\text { Tidak ada } \\
\text { tepukan tangan }\end{array}$ & Non Aktif & Non Aktif & Non Aktif & Non Aktif \\
\hline 11 & $\begin{array}{l}\text { Tidak ada } \\
\text { orang }\end{array}$ & $<200$ & $<28$ & $\begin{array}{l}\text { Tidak ada } \\
\text { tepukan tangan }\end{array}$ & Non Aktif & Non Aktif & Non Aktif & Non Aktif \\
\hline 12 & $\begin{array}{l}\text { Tidak ada } \\
\text { orang }\end{array}$ & $<200$ & $>28$ & $\begin{array}{c}\text { Tidak ada } \\
\text { tepukan tangan }\end{array}$ & Non Aktif & Non Aktif & Non Aktif & Non Aktif \\
\hline
\end{tabular}

Sebaliknya, ketika tidak ada orang dalam ruang kelas, maka semua perangkat menjadi non aktif. Hasil deteksi sensor suara FC-04 akan mengaktifkan proyektor saat ada suara tepukan tangan yang terdeteksi. Selanjutnya jika kembali ada tepukan tangan yang terdeteksi, maka proyektor menjadi non aktif.

\section{Penutup}

\section{A. Kesimpulan}

1. Sensor PIR dalam rancangan prototipe sistem otomatisasi mampu mendeteksi keberadaan orang hingga jarak 7 meter.

2. Jika sensor PIR mendeteksi keberadaan orang dalam ruang kelas, maka listrik dalam ruang kelas akan aktif berdasarkan proses kendali oleh Arduino Uno.

3. Lampu dalam ruang kelas akan aktif bila Arduino Uno menerima hasil deteksi sensor LDR saat intensitas cahaya kurang dari 200 Lux.
4. Kipas angin dalam ruang kelas akan aktif berdasarkan sinyal kendali dari Arduino Uno bila sensor LM35 mendeteksi suhu dalam ruang kelas diatas $28^{\circ} \mathrm{C}$.

5. Setiap kenaikan suhu $1^{\circ} \mathrm{C}$ tegangan sensor LM35 rata-rata naik sebesar $10 \mathrm{mV}$.

6. Proyektor dalam ruang kelas akan aktif bila Arduino Uno menerima masukan dari sensor FC-04 yang mendeteksi adanya suara tepukan tangan, dan proyektor manjadi non aktif bila sensor FC-04 kembali mendeteksi adanya suara tepukan tangan berikutnya.

\section{B. Saran}

1. Prototipe sistem otomatisasi ini agar dicoba dan diaplikasikan dalam ruang kelas.

2. Sistem otomatisasi dapat dikembangkan dan diperbaiki lagi terutama dengan perintah mengaktifkan dan menon-aktifkan proyektor yang lebih spesifik dan jelas. 


\section{REFERENSI}

[1] Sutono, "Perancangan Sistem Aplikasi Otomatisasi Lampu Penerangan Menggunakan Sensor Gerak Dan Sensor Cahaya Berbasis Arduino Uno (Atmega 328)", Majalah Ilmiah UNIKOM, Vol. 12, No. 2, hal. 223-232, 2014.

[2] E. Desyantoro, A.F. Rochim, dan K.T. Martono, "Sistem Pengendali Peralatan Elektronik Dalam Rumah Secara Otomatis Menggunakan Sensor PIR, Sensor LM35, dan Sensor LDR", Jurnal Teknologi dan Sistem Komputer, Vol. 3, No. 3, hal. 405-411, 2015.

[3] C.W. de Silva, "Sensor systems: fundamentals and applications", CRC Press, Boca Raton, 2017.

[4] R. Toyib, I. Bustami, D. Abdullah, dan Onsardi, "Penggunaan Sensor Passive Infrared Receiver (Pir) Untuk Mendeteksi Gerak Berbasis Short Message Service Gateway”, Jurnal Pseudocode, Vol. VI, No. 2, hal. 114-124, 2019.

[5] ___ "Sensor Cahaya LDR (Light Dependent Resistor)”, [Internet] Elektronika Dasar, 29 Juli 2021, dikunjungi 2
Oktober 2021, tersedia dari: https://elektronikadasar.web.id/sensor-cahaya-ldr-light-dependent-resistor/.

[6] N.A. Junizan, A.A. Razak, B. Balakrishnan, dan W.A.F.W. Othman, "Design and Implementation of Automatic Room Temperature Controlled Fan using Arduino Uno and LM35 Heat Sensor", International Journal of Engineering Creativity and Innovation, Vol. 1, No. 2, hal. 8-14, 2019.

[7] M. Damirchi, "Interfacing FC-04 Microphone Sound Sensor Module with Arduino", [Internet] ElectroPeak, dikunjungi 2 Oktober 2021, tersedia dari: https://electropeak.com/learn/interfacing-fc-04microphone-sound-sensor-module-with-arduino/.

[8] O.B. Kharisma, dan H.B.P. Utama, "Pengembangan Sistem Pengaman Pintu Laboratorium Robotika Uin Sultan Syarif Kasim Berdasarkan Siulan Berbasis Sensor Fc-04 Dan Mikrokontroler Atmega 328", Jurnal Sains dan Teknologi, Vol. 7, No. 1, hal. 114-125, 2018.

[9] I. Susanto, "Microcontroller: Menguasai Arduino", Teknosain, Yogyakarta, 2018. 